\title{
Analisis Kepuasan Konsumen Kereta Api Indonesia Terhadap Pelayanan Selama Masa Pandemi Covid-19 (Studi Kasus Stasiun Maguwoharjo DIY)
}

\author{
Bagus Gilang Prasetyo ${ }^{1)}$, Satria Agung Wibawa ${ }^{2)}$ \\ 1) Fakultas Teknik, Program Studi Teknik Sipil, Universitas Veteran Bangun Nusantara, Sukoharjo, \\ Jl. Letjen Sudjono Humardhani, No.1, Jombor, Sukoharjo; Telp. 0271-593156. \\ Email: bagusgilangprasetyo@gmail.com \\ 1) Fakultas Teknik, Program Studi Teknik Sipil, Universitas Veteran Bangun Nusantara, Sukoharjo, \\ J1. Letjen Sudjono Humardhani, No.1, Jombor, Sukoharjo; Telp. 0271-593156. \\ Email: zatrea_wawa@gmail.com
}

\begin{abstract}
Abstrak
Penelitian ini dilakukan untuk mengetahui kepuasan konsumen terhadap pelayanan stasiun Maguwoharjo DIY, dengan menerapkan model observasi pelayanan stasiun selama pandemi covid -19 untuk memperoleh data yang diperlukan dalam penelitian ini. Menggunakan metode dengan menyebarkan kuesioner dan melakukan wawancara, dokumentasi dengan sampel 100 responden kepada setiap konsumen dikawasan stasiun Maguwoharjo DIY. Lingkup peneltian ini berdasarkan pelayanan stasiun selama pandemi covid -19. Adapun hasil yang diperoleh data yang diolah oleh penulis dari analisis deskriptif dan regensi linier berganda maka menunjukan variable terhadap pelayanan stasiun. Dengan nilai sebesar 4,509, 4,649 dan 4,437 nilai ini termasuk dalam katagori dangat tinggi yang diberikan oleh pihak konsumen, dengan hasil 512 dan -1370 dari kelima dimensi bukti langsung, kehandalan, daya tanggap, jaminan, empati maka, tidak bepengaruh terhadap kepuasan konsumen pengguna jasa model trasnportasi umum di stasiun Maguwoharjo DIY selama pandemi covid - 19.
\end{abstract}

Kata kunci: kereta api, kepuasan konsumen, pelayanan.

\begin{abstract}
This study was conducted to determine customer satisfaction with the services of the Maguwoharjo DIY station, by applying the station service observation model during the covid -19 pandemic to obtain the data needed in this study. Using the method by distributing questionnaires and conducting interviews, documentation with a sample of 100 respondents to each consumer in the Maguwoharjo DIY station area. The scope of this research is based on station services during the COVID-19 pandemic. As for the results obtained by the data processed by the author from descriptive analysis and multiple linear regression, it shows the variable on station service. With a value of 4,509, 4.649 and 4,437 this value is included in the very high category given by the consumer, with the results of 512 and -1370 from the five dimensions of direct evidence, reliability, responsiveness, assurance, empathy so, it does not affect customer satisfaction of service users. public transportation model at Maguwoharjo DIY station during the Covid-19 pandemic.
\end{abstract}

Keywords: customer satisfaction, train, service.

\section{PENDAHULUAN}

Transportasi kereta api dalam perannya sekarang sangat berguna bagi masyarakat daerah maupun kota dan provinsi setempat dengan pelayanan dari prasarana dan sarana yang mulai nyaman dan aman koefisien tepat waktu, penumpang memiliki karasteriktik yang sangat nominal yang berkaitan dengan keungulan dan kelemahan. Karasteriktik perkeretaapian adalah yang perlu dikembangkan menurut Peraturan Pemerintah Republik Indonesia (PP) Nomor 69 Tahun 1998.
Jasa merupakan segala aktifitas atau manfaat yang dapat ditawarkan oleh satu pihak kepada pihak lain yang pada dasarnya tidak berwujud dan tidak menghasilkan kepemilikan apapun, menurut Kotler dan Amstrong (2012). Kegiatan ekonomi dan transportasi memiliki keterkaitan yang sangat erat, di negara ini dimana keduanya dapat saling mempengaruhi dan berkaitan. Hal ini seperti yang diungkapkan oleh, bahwa pertumbuhan ekonomi memiliki keterkaitan pembangunan infrastruktur dengan moda transportasi, karena akibat pertumbuhan ekonomi yang mulai meningkat maka mobilitas seseorang akan dan kebutuhan pergerakannya 
berupa mesin dan teknologi pun menjadi meningkat melebih kapasitas prasarana transportasi yang tersedia di negara kita (Tamin, 2000).

Stasiun sebagai salah satu simpul transportasi memiliki peran penting dalam penyelenggaraan perkeretaapian, excellent service merupakan bagian dari sasaran PT. Kereta Api Indonesia (Persero) untuk memaksimalkan upaya dalam inovasi pelayanannya, dimana salah satunya implementasinya adalah dengan keberadaan Stasiun Kereta Api (Riyanto dan Riyanto, 2015). Stasiun KA merupakan tempat untuk menaikkan dan menurunkan penumpang yang menggunakan jasa transportasi kereta api. Stasiun besar biasanya diberi perlengkapan yang lebih banyak dari pada stasiun kecil untuk menunjang kenyamanan penumpang maupun calon penumpang kereta api (Intari et.al, 2017).

Pada ondisi pandemi covid-19 diterbitkan peraturan baru pada transportasi umum dalam Permenhub Nomor 41 Tahun 2020 dimana kapasitas darat laut dan udara maupun kereta api di batasi maksimal 50\% dari kapasitas.

Berdasarkan hasil observasi di lapangan masih banyak ditemukan keluhan masyarakat terhadap pelayanan di stasiun maguwoharjo yang masih belum optimal selama masa pandemi covid-19 dalam memberikan pelayanan terhadap pengguna jasa terutama dalam hal penyedian pokok, penunjang, dan fasilitas khusus yang ada di Stasiun antara lain seringnya keterlambatan jadwal keberangkatan dan kedatangan kereta api sehingga menimbulkan kepadatan di stasiun, juga ketersediaan informasi dan layanan pendukung lainnya. Berdasarkan masalah di atas, maka tujuan penelitian tindakan permasalahan untuk mengetahui nilai tingkat kepuasan konsumen KAI Stasiun Maguwoharjo DIY selama pandemi covid-19 serta untuk mengetahui hubungan antara pelayanan dengan tingkat kepuasan konsumen KAI Stasiun Maguwoharjo selama pandemi covid-19.

\section{METODE}

\section{Pendekatan Penelitian}

Pendekatan penelitian ini menitikberatkan pada pengupayaan pemanfaatan moda transportasi darat alternatif selain transportasi rel kereta api guna memenuhi kebutuhan akan permintaan konsumen. Pengambilan sampel data $100 \%$ responden. Variabel-variabel yang dianggap mempengaruhi pengguna jasa angkutan darat (Kereta Api Indonesia) di Stasiun Maguwoharjo DIY, beserta batasan-batasannya adalah umur, jenis kelamin, jenis pekerjaan, tujuan perjalanan, dan frekuensi mengunakan moda transportasi umum.

\section{Alur Penelitian}

Metodologi penelitian bersetujuan untuk menyelesaikan suatu permasalahan yang ada secara terstruktur dalam pembagian dari Flow Chart pada Gambar 1.

\section{Obvervasi Pendahuluan}

Peneliti melakukan pengamatan dengan melakukan obvervasi kondisi lokasi sekitar penelitian yaitu di daerah Stasiun Maguwoharjo DIY. Dari hasil pengamatan maka peneliti melakukan penelitian dengan metode Analisis dengan mengunakan metode Mic Excel, Software Statistical Product and Service Solution (SPSS). untuk mengetahui kinerja pelayanan yang meliputi kualitas dan fasilitas yang diberikan oleh penyedia jasa Kereta Api Indonesia.

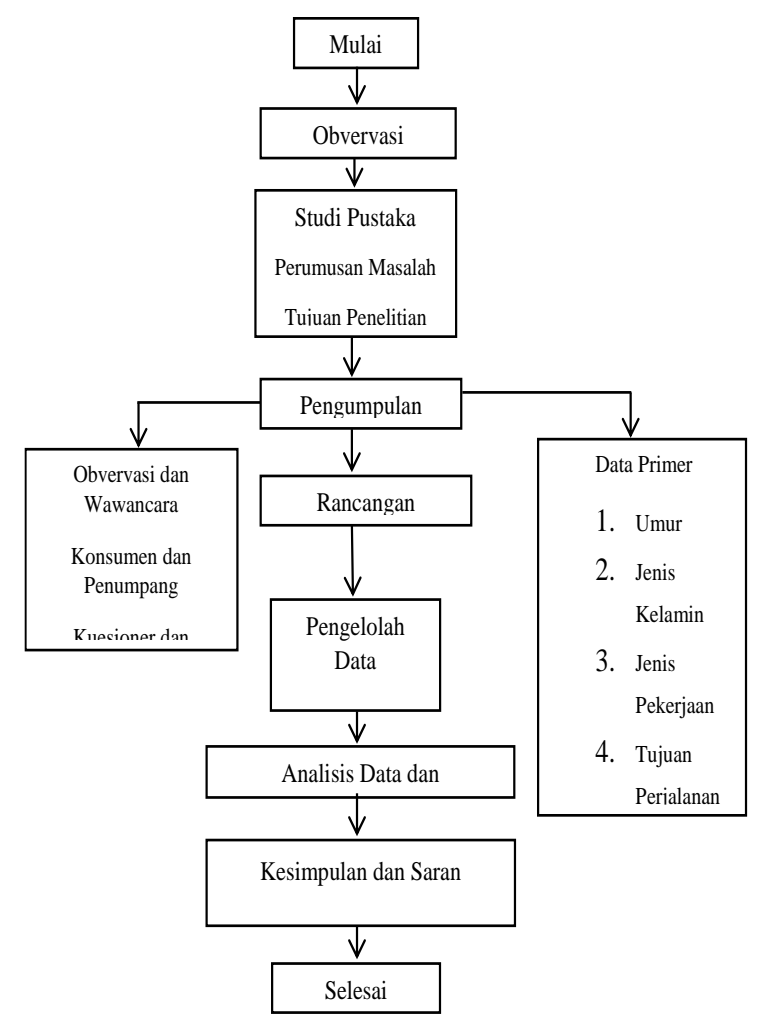

Gambar 1. Flow Chart Diagram Alir Penelitian 


\section{Pengumpulan Data}

Pada tahap pengumpulan data yang di butuhkan di kelompokan sebagai berikut adalah:

\section{Obvervasi}

Pengamatan adalah suatu aktivitas terhadap suatu proses atau objek dengan maksud merasakan kemudian memahami suatu kondisi di lapangan di Area Stasiun Maguwoharjo DIY berdasarkan penegetahuan dan gagasan yang sudah di ketahuhi sebelumnya untuk mendapat informasi-informasi untuk melanjutkan suatu penelitian

\section{Wawancara}

Salah satu metode pengumpulan data yang paling utama dalam mencari responden adalah melalui wawancara yaitu mendapat informasi dengan cara tanya jawab langsung kepada responden. Wawancara adalah bagian terpenting dalam survey tanpa wawancara maka peniliti akan kehilangan informasi.

\section{Data Primer}

Data yang diperoleh dengan peninjauan secara langsung (Obvervasi). Di lokasi Stasiun Maguwoharjo DIY.dengan cara wawancara dengan responden pengawasan terhadap kepuasan konsumen fasilitas stasiun Maguwoharjo DIY Selama Pandemi Covid 19. Dengan mengumpulkan sampel populasi dengan mengisi koesioner yang dibuat oleh peneliti. Untuk tujuan tercapainya proses analisis suatu, dapat dibagi menjadi : Umur, Jenis Kelamin, Jenis Pekerjaan, Tujuan Perjalanan, Frekuensi Mengunakan Moda Transportasi Umum

\section{Rancangan Koesioner}

Dalam merancang kuesioner, penentuan variabel-variabel karakteristik pengguna jasa didapatkan dari studi pustaka sebagai data kualitatif. Agar tujuan dan manfaat penelitian terpenuhi, pada kuesioner ditambahkan pulasaran-saran dan masukan tentang sarana penunjang terhadap fasilitas stasiun Maguwoharjo DIY selama Pandemi Covid.

\section{Pengelolah Data}

Pengelolah data yang diperoleh dari hasil pengumpulan data responden/konsumen. Untuk mendaptakan tujuan dari peneliti, penegelolah data di lakukan melalui Program Software Statistical Product and Service Solution (SPSS).
Pengelolah data bersetujuan agar data mentah yang diperoleh bisa di analisa dan kemudian memudahkan dalam membuat kesimpulan dan mendaptkan jawaban dari permasalahan yang sedang diselesaikan.

\section{HASIL DAN PEMBAHASAN}

\section{Deksripsi Konsumen dan Analisis Dekritif}

Analisis deskriptif maka penggambaran yang dideskriptifkan dari data-data yang dapat diperoleh melalui peneliti selama di lapangan, dengan mengunakan analisis data berupa deskriptif yang biasanya berupa mengenai identitas diri mulai dari jenis kelamin, usia, pendidikan, dan lain sebagainya. Metode ini menurut penulis bertujuan untuk menguraikan data-data hasil penelitian yang telah dilakukan dilapangan mengenai sifat-sifat maupun karakteristik dari suatu keadaan di lapangan dengan membuat deskripsi atau gambaran mengenai fakta-fakta maupun sifat-sifat dari fenomena dilapangan yang telah diselidiki oleh peneliti Menurut Ghozali (2009) analisis dektiritif ini bertujuan untuk memberikan gambaran langsung atau mendeskripsikan suatu data dalam variabel yang dilihat dari nilai ratarata (mean), minimum, maksimum, dan standar deviasi. Metode pengujian yang dilakukan penulis menggunakan aplikasi Ms. Excel. Hasil dan pembahasan berisi hasil-hasil temuan penelitian dan pembahasannya secara ilmiah. Tuliskan temuan-temuan ilmiah yang diperoleh dari hasil-hasil penelitian yang telah dilakukan tetapi harus ditunjang oleh data-data yang memadai. Temuan ilmiah yang dimaksud di sini adalah bukan data-data hasil penelitian yang diperoleh.

\section{Analisis Dekritif Responden}

Analisis deskriptif yang dilakukan oleh penulis untuk mendekripsikan atau memberikan suatu gambaran yang berupa data mengenai identitas diri yang dimulai dari jenis kelamin, usia, tujuan perjalanan, pekerjaan, dan jumlah penggunaan moda transportasi selama beberapa bulan terakhir. data yang diperoleh selama dilapangan untuk memudahkan pembaca dan merupakan hasil bahasan penulis dalam tugas akhir ini. Adapun hasil analisis deskriptif responden yang dilakukan oleh penulis adalah: Analisis Deskriptif Kepuasan Responden Pelayanan fasilitas Stasiun Maguwoharjo Daerah Istimewa Yogyakarta terhadap Kepuasan Konsumen selama Pandemi Covid 19. 


\section{Analisis Respoden Terhadap Konsumen}

Untuk lebih jelasnya peneliti sekaligus penulis. memberikan gambaran seperti dibawah ini dalam penyajian diagram tabel, pembaca, dalam memahami hasil penelitian penulis, terlihat seperti pada Tabel 1, Analisis Responden Terhadap Kepuasan Konsumen

Tabel 1. Analisis Responden Terhadap Kepuasan Konsumen

\begin{tabular}{|c|c|c|c|}
\hline No & Keterangan & $\begin{array}{l}\text { Ket } \\
\text { Jumlah }\end{array}$ & $\begin{array}{l}\text { Presentase } \\
\text { Responden }\end{array}$ \\
\hline 1 & Jenis Kelamin & Jumlah & Presentase \\
\hline 1 & Laki Laki & 60 & $60 \%$ \\
\hline 2 & Perempuan & 40 & $40 \%$ \\
\hline Total & Jumlah & 100 & $100 \%$ \\
\hline 2 & $\begin{array}{l}\text { Umur Anda } \\
\text { Saat Ini }\end{array}$ & Jumlah & Presentase \\
\hline 1 & $<20$ & 4 & $4 \%$ \\
\hline 2 & $21-30$ & 50 & $50 \%$ \\
\hline 3 & $31-40$ & 27 & $27 \%$ \\
\hline 4 & > 41 / Lanjut & 19 & $19 \%$ \\
\hline Total & Jumlah & 100 & $100 \%$ \\
\hline 3 & Tujuan & Jumlah & Presentase \\
\hline 1 & Irit Biaya & 30 & $30 \%$ \\
\hline 2 & $\begin{array}{l}\text { Mengindari } \\
\text { Macet }\end{array}$ & 40 & $40 \%$ \\
\hline 3 & $\begin{array}{l}\text { Mencari Aman } \\
\text { dan Nyaman }\end{array}$ & 30 & $30 \%$ \\
\hline Total & Jumlah & 100 & $100 \%$ \\
\hline 5 & Pekerjaan & Jumlah & Presentase \\
\hline 1 & $\begin{array}{l}\text { Pelajar } \\
\text { Mahasiswa }\end{array}$ & 30 & $30 \%$ \\
\hline 2 & $\begin{array}{l}\text { Pegawai Negri } \\
\text { Sipil }\end{array}$ & 20 & $20 \%$ \\
\hline 3 & Pegawai Swasta & 35 & $35 \%$ \\
\hline 4 & DLL & 15 & $15 \%$ \\
\hline Total & Jumlah & 100 & $100 \%$ \\
\hline
\end{tabular}

\section{Kriteria Analisis Responden Terhadap Konsumen}

Berdasarkan analisis responden dengan hasil Olah Data, adalah terhadap kepuasan konsumen fasilitas stasiun yang terdapat pada tabel menunjukan bahwa karasteristik dan tangapan konsumen dan penguna yang sekaligus mengunakan jasa transportasi Kereta Api Indonesia Persero.

Sebagai peneyedia jasa transportasi daerah operasi DAOP VI Daerah Operasi Daerah Istimewa Yogyakarta. Berdasarkan tangapan Konsumen dari hasil koesioner yang tersebar dapat di jelaskan secara lengkap dan mudah seperti berikut adalah:

1. Diketahui bahwa responden yang mengisi kuisioner mayoritas adalah responden lakilaki yaitu berjumlah 60 responden atau sebesar $60 \%$ dan responden Perempuan berjumlah 40 responden 40 atau sebesar $40 \%$.

2. Diketahui bahwa responden yang mengisi kuisioner mayoritas adalah responden Umur < 20 yaitu berjumlah 4 responden atau sebesar 4\% dan responden Umur 21 - 30 berjumlah 50 responden atau sebesar $50 \%$ responden dan Umur $31-40$ yaitu berjumlah 27 responden atau sebesar $27 \%$ responden > 41 / Lanjut yaitu berjumlah 9 responden 19 atau sebesar $19 \%$.

3. Diketahui bahwa karasteristik responden yang mengisi kuisioner mayoritas adalah responden Irit Biaya 30 yaitu berjumlah 30 responden atau sebesar $30 \%$ dan Mengindari Macet 40 berjumlah 40 responden atau sebesar $40 \%$ responden dan responden Mencai Aman dan Nyaman yaitu berjumlah30 responden 30 atau sebesar $30 \%$.

4. Karasteristik responden yang mengisi kuisioner mayoritas adalah responden Frekuensi Konsumen mengunakan transportasi umum 1-2 Kali 28 yaitu 29 responden atau sebesar $28 \%$ dan Frekuensi 3-4 Kali 15 berjumlah 15 responden atau sebesar $15 \%$ responden dan responden Berkali-Kali yaitu berjumlah 55 responden 55atau sebesar $55 \%$.

5. Karasteristik responden yang mengisi kuisioner mayoritas adalah responden Berdasarkan Pekerjaan Konsumen Pelajar/Mahasiswa13 yaitu 30 responden atau sebesar 30\% dan Pegawai Negri Sipil 20 berjumlah 20 responden atau sebesar 20 $\%$ responden dan responden Pegawai Swasta yaitu berjumlah 35 responden 35 atau sebesar 35\%. Responden DLL 
responden 15 berjumlah 15 atau sebesar $15 \%$.

6. Setelah penulis melakukan penelitian dilapangan mengenai kepuasan terhadap fasilitas pelayanan konsumen yang menggunakan moda transportasi kereta api Indonesia. Berdasarkan tanggapan responden dari hasil kuesioner dan telah di olah oleh penulis, maka dapat dijelaskan secara lengkap sebagai berikut:

a) Dari butir jawaban atau pernyataan variabel terhadap pelayanan fasilitas stasiun yang paling tinggi dengan skor rata-rata 4,730 atau 4,73. Sedangkan butir jawaban atau pernyataan variabel kualitas pelayanan yang paling rendah dengan skor rata-rata 4,370 atau 4,37.

b) Dari butir jawaban atau pernyataan terhadap pengawasan fasilitas stasiun yang paling tinggi dengan skor rata-rata 4,890 atau 4,89 . Sedangkan butir jawaban atau pernyataan variabel terhadap pelayanan fasilitas stasiun yang paling rendah dengan skor 4,550 atau 4,550.

c) Dari butir jawaban atau pernyataan variabel kepuasan konsumen 4,555 atau 4,55. Sedangkan butir jawaban atau pernyataan variabel 4,396 atau 4,39.

\section{Teknik Analisis Data Uji Validitas}

Uji validitas untuk mengukur sah atau tidak sah nya suatu kuisioner. Kuisioner dikatakan valid apabila pertanyaan pada kuisioner mampu mengungkap sesuatu yang akan diukur oleh kuisioner tersebut.

Tabel 2. Hasil Uji Relibilitas Pengawasan Fasilitas Stasiun

\begin{tabular}{ll}
\hline Reliability Statistics & \\
\hline Cronbach's Alpha & N of Items \\
.279 & 9 \\
\hline
\end{tabular}

Sumber: Hasil Olah Data SPSS 2021

Tabel 3. Hasil Uji Relibilitas kepuasan Konsumen

\begin{tabular}{ll}
\hline Reliability Statistics & \\
\hline Cronbach's Alpha & N of Items \\
.294 & 6 \\
\hline
\end{tabular}

Sumber.Hasil Olah Data SPSS 2021
Berdasarkan tabel 4 atau tepatnya tabel nilai koefisien $r$ hitung dengan rentang nilai Cronbach alpha untuk setiap variabel Terhadap pelayanan, Pengawasan fasilitas, dan Kepuasan Konsumen. Berdasarkan butir-butir pertanyaan yang diberikan dan di isi oleh responden menunjukkan bahwa jawaban atau pernyataan dengan nilai Cronbach's Alpha $>0,60$. Disimpulkan data relibilitas untuk semua pernyataan dapat dinyatakan konsisten (reliabel) atau moderat.

Tabel 4. Kesimpulan Uji Relibilitas

\begin{tabular}{ccccc}
\hline No & Variabel & $\begin{array}{c}\text { Rentang } \\
\text { Nilai } \\
\text { Cronbac } \\
\text { h alpha }\end{array}$ & $\begin{array}{c}\text { r } \\
\text { hitun } \\
\mathbf{g}\end{array}$ & Keterangan \\
\hline 1 & $\begin{array}{l}\text { Terhadap } \\
\text { Pelayanan }\end{array}$ & 0,60 & 0,258 & $\begin{array}{c}\text { Reliabel/moder } \\
\text { at } \\
\text { Reliabel/moder } \\
\text { at }\end{array}$ \\
2 & $\begin{array}{l}\text { Pengawasa } \\
\text { n Fasilitas }\end{array}$ & 0,60 & 0,279 & $\begin{array}{c}\text { Reliabel/moder } \\
\text { at }\end{array}$ \\
\hline 3. & $\begin{array}{l}\text { Kepuasan } \\
\text { Konsumen }\end{array}$ & 0,60 & 0,294 & \\
\hline Sumber:Hasil Olah Data SPSS 2021 &
\end{tabular}

\section{Uji Heteroskedastisitas}

Dalam uji heteroskedastisitas ini berdasarkan metode genjer dimana dalam. data-data dikatakan tidak terjadi masalah, apabila tidak terjadi gejala heteroskedastisitas. Data yang diperoleh melalu hasil survey, kemudian di olah oleh peneliti, serta di uji melalui aplikasi atau Software Statistical Product and Service Solution (SPSS 22.0). Adapun hasil uji heteroskedastisitas menggunakan metode uji scatterplot yang di uji oleh penulis adalah sebagai berikut:

Tabel 5. Hasil Uji Heteroskedastisitas

\begin{tabular}{|c|c|c|c|c|c|}
\hline \multicolumn{6}{|c|}{ Coefficients $^{a}$} \\
\hline \multirow[t]{2}{*}{ Model } & $\begin{array}{r}\text { Unstand } \\
\text { Coeffi }\end{array}$ & $\begin{array}{l}\text { ardized } \\
\text { cients }\end{array}$ & $\begin{array}{c}\text { Standar } \\
\text { dized } \\
\text { Coefficie } \\
\text { nts } \\
\end{array}$ & \multirow{2}{*}{\multicolumn{2}{|c|}{ Sig. }} \\
\hline & B & $\begin{array}{l}\text { Std. } \\
\text { Error }\end{array}$ & Beta & & \\
\hline 1 (Constant) & -10.009 & 6.388 & & -1.567 & .120 \\
\hline $\begin{array}{l}\text { PELAYANAN } \\
\mathrm{X} 1\end{array}$ & .056 & .057 & .099 & .983 & .328 \\
\hline $\begin{array}{l}\text { FASILITAS } \\
\mathrm{X} 2\end{array}$ & .240 & .163 & .148 & 1.473 & .144 \\
\hline
\end{tabular}

\section{Hasil.Olah Data SPSS 2021}

Berdasarkan Tabel 5 dapat dilihat bahwa hasil dari nilai koefisien $r$ hitung dengan $r$ tabel untuk setiap variabel terhadap pelayanan, pengawasan fasilitas pelayanan, dan kepuasan konsumen. 
Berdasarkan butir-butir pertanyaan yang diberikan dan di isi oleh responden menunjukkan bahwa jawaban atau pernyataan ( $r$ hitung $\geq r$ tabel $(0,163)$. Sehingga dapat disimpulkan untuk semua pernyataan dapat valid.

Berdasarkan tabel 5, dapat dilihat bahwa hasil dari pengujian uji heteroskedastisitas, untuk setiap variabel kualitas pelayanan (X1) dan fasilitas pelayanan (X2) menunjukkan nilai signifikansi masing-masing sebesar 0,328 dan 0,144 atau $(\mathrm{P}>0,05)$, sehingga hasil tersebut lebih besar dari nilai standar signifikansi 0,05 . Sehingga hasil uji heteroskedastisitas dapat disimpulkan untuk variabel kualitas pelayanan (X1) dan fasilitas pelayanan (X2) dapat dinyatakan tidak terjadi masalah heteroskedastisitas. Berdasarkan hasil pengujian diatas dengan menggunkan metode glejser, dapat disimpulkan bahwa, untuk setiap variabel Terhadap pelayanan (X1) dan pengawasan fasilitas (X2) tidak menunjukkan gejala heteroskedastisitas, sehingga dapat dinyatakan tidak terjadi masalah heteroskedastisitas.

\section{Uji Relibilitas}

Data yang diperoleh melalu hasil survey, kemudian di olah oleh peneliti, serta di uji melalui aplikasi atau Software Statistical Product and Service Solution (SPSS 22.0). Pengujian pada analisis data ini bertujuan untuk mengetahui konsistensi kuesioner (instrument penelitian) untuk sebuah penelitian.

Tabel 6. Hasil Uji Relibilitas Terhadap Pelayanan Stasiun

\begin{tabular}{ll}
\hline Reliability Statistics & \\
\hline Cronbach's Alpha & N of Items \\
.258 & 9 \\
\hline
\end{tabular}

Sumber.Hasil Olah Data SPSS 2021

\section{Analisis Regensi Linear Berganda}

Dalam pengujian analisis regresi linear berganda ini adalah untuk mengetahui ada atau tidaknya pengaruh dua atau lebih variabel bebas (X) terhadap variabel terikat $(\mathrm{Y})$. Data yang diperoleh melalu hasil survey, kemudian di olah oleh peneliti, serta di uji melalui aplikasi atau Software Statistical Product and Service Solution (SPSS 22.0). Adapun hasil uji analisis regresi linear berganda yang di uji oleh penulis adalah sebagai berikut :

\section{Uji T}

Uji T dilakukan oleh penulis untuk mengetahui apakah kinerja pelayanan yang berupa kualitas dan fasilitas berpengaruh terhadap kepuasan konsumen atau penumpang secara secara parsial.

Tabel 6. Uji T

\begin{tabular}{|c|c|c|c|c|c|}
\hline \multicolumn{6}{|c|}{ Coefficients $^{a}$} \\
\hline \multirow[t]{2}{*}{ Model } & $\begin{array}{l}\text { Unstand } \\
\text { Coeffi }\end{array}$ & $\begin{array}{l}\text { ardized } \\
\text { cients }\end{array}$ & $\begin{array}{c}\text { Standar } \\
\text { dized } \\
\text { Coefficie } \\
\text { nts }\end{array}$ & \multirow[t]{2}{*}{$\mathbf{t}$} & \multirow[t]{2}{*}{ Sig. } \\
\hline & B & $\begin{array}{c}\text { Std. } \\
\text { Error }\end{array}$ & Beta & & \\
\hline 1 (Constant) & 38.798 & 5.089 & & 7.624 & .000 \\
\hline XI & -.065 & .100 & -.066 & -.648 & .518 \\
\hline $\mathrm{X} 2$ & -.255 & . 105 & -.247 & -2.430 & .017 \\
\hline
\end{tabular}

Hasil.Olah Data SPSS 2021

Berdasarkan tabel 6 dapat dilihat bahwa hasil dari pengujian uji analisis regresi linear berganda, sehingga dapat ditarik kesimpulan berdasarkan hipotesis penulis sebagai berikut :

\section{Pengujian hipotesis pertama (H1)}

Diketahui nilai Sig untuk pengaruh terhadap pelayanan (XI) terhadap kepuasan konsumen (Y) adalah sebesar nilai $t$ hitung $-648>t$ tabel 1,984, sehingga dapat disimpulkan bahwa $\mathrm{H} 1$ tolak dan $\mathrm{H} 2$ diterima yang berarti terdapat pengaruh pengaruh tehadap pelayanan selama Pandemi Covid 19 (XI) terhadap kepuasan konsumen (Y)

\section{Pengujian hipotesis kedua (H2)}

Diketahui nilai Sig untuk pengaruh fasilitas pelayanan (X2) terhadap kepuasan konsumen (Y) adalah sebesar nilai t hitung $-2.430>t$ tabel 1,984, sehingga dapat disimpulkan bahwa $\mathrm{H} 2$ diterima dan $\mathrm{H} 1$ ditolak yang berarti tidak terdapat pengaruh terhadap pelayanan stasiun selama pandemi covid 19 (XI) terhadap kepuasan konsumen $(\mathrm{Y})$.

\section{SIMPULAN}

Berdasarkan hasil olah data yang diolah oleh penulis dari hasil analisis deskriptif menunjukkan bahwa untuk variabel terhadap pelayanan, stasiun ,dan kepuasan konsumen, menunjukkan nilai sebesar 4,509, 4,694, dan 4,437 nilai ini termasuk kedalam kategori sangat tinggi, sehingga dapat disimpulkan bahwa 
penilaian penumpang, pengunan jasa, konsumen yang diberikan terhadap pelayanan yang diberikan oleh pihak stasiun maguwoharjo DIY selama pandemi covid-19, terhadap pelayanan kepuasan konsumen sangat baik.

Pengaruh terhadap pelayanan yang di berikan stasiun Maguwoharjo DIY, selama pandemi covid-19 terhadap kepuasan konsumen sangat berpengaruh terhadap pelayanan stasiun sebagai berikut:

a) Dari hasil olah, dengan pengujian analisis regensi linear berganda, maka disimpulkan terhadap kepuasan pelayanan stasiun maguwoharjo DIY selama pandemi covid19, dengan hasil 512, sehinga pelayanan bukti langsung, kehandalan, daya tangap, jaminan, empati tidak berpengaruh kepada kepuasan konsumen di stasiun maguwoharjo DIY.

b) Dari hasil olah data stasiun maguwoharjo DIY menunjukan kelima dimensi pelayanan jasa yaitu, bukti langsung, kehandalan, daya tangap, jaminan, empati dengan hasil -1370, sehinga stasiun maguwoharjo DIY selama pandemi covid19, tidak berpengaruh terhadap kepuasan konsumen penguna jasa moda transportasi umum selama pandemi covid-19, stasiun maguwoharjo DIY.

\section{UCAPAN TERIMAKASIH}

Ucapan terima kasih kpeada Prodi Teknik Sipil

Universitas Veteran Bangun Nusantara Sukoharjo yang telah mendukung terselesaikannya penelitian ini.

\section{DAFTAR PUSTAKA}

Ghozali,I., 2011. Aplikasi Analisis Multivariate Dengan Program SPSS. Semarang: Badan.Penerbit. Undip.

Intari, D. E., Suryani, I., \& Septya, I. 2017. Evaluasi Kinerja Pelayanan Stasiun.

Kotler, P., \& Amstrong, G. 2012. Manajemen Pemasaran. Jakarta: PT Indeks, Kelompok, Gramedia.

Peraturan Pemerintah Republik Indonesia (PP) Nomor 69 Tahun 1998 (69) Tentang Prasarana dan Sarana Kereta Api

Riyanto, A. h., \& Riyanto, B. 2015. Analisis Peningkatan Pelayanan Stasiun Bogor Terhadap Kepuasan Pengguna Jasa Kereta Api Dengan Metode Importance Performance Analysis (IPA). Jurnal Pembangunan Wilayah dan Kota, 391-402.

Tamin, Ofyar Z. 2000. Perencanaan dan pemodelan transportasi. Penerbit ITB, Bandung. 